\title{
Guest editorial: Shifting boundaries of elder care: changing roles and responsibilities
}

\author{
Tine Rostgaard $\cdot$ Minna Zechner
}

Published online: 8 May 2012

(C) Springer-Verlag 2012

This thematic section of the European Journal of Ageing addresses care for older people in a number of European countries, in regards to the consequences that shifting boundaries of responsibility for financing, organising and providing care have had for older persons as care recipients and for informal and formal care workers. The initiative for this section comes from the Nordic Centre of Excellence: 'Reassessing the Nordic Welfare Model' (REASSESS) and within this from the strand 'Care in ageing and diversifying societies'. The interest in the consequences of the shifting boundaries of care stems from the major changes that European welfare states and elder care policies have been facing in recent decades. These changes and re-structuring processes of care policies and service provision have changed the situation of carers considerably, both in the informal and formal sector, of older people in need of care and their members of kin. Care policies compose the structural environment of elder care and changes in it have many intended and unintended consequences for different actors; informal and formal carers, elders and their kin members.

The overarching trend in elder care during recent decades seems to have been the politisation of care, meaning that care for older people has increasingly become a political matter that requires actions from decision-makers and public bodies. One evident consequence of politisation of care is the formalisation of care practices and relations.

T. Rostgaard $(\square)$

Department of Political Science, Aalborg University,

Aalborg, Denmark

e-mail: tr@dps.aau.dk

M. Zechner

Seinäjoki University of Applied Sciences, Seinäjoki, Finland
Formalisation means that public involvement in financing, regulating, organizing and providing care is increasing. This does not necessarily mean that more public elder care services are produced across Europe. It may as well mean that by offering cash allowances to support informal care given by intimates, the work of informal carers is for example regulated by agreements and contracts.

Cash benefits in informal care have led to what has been termed semi-formalisation (Geissler and Pfau-Effinger 2005) of care where formal agreements and money have entered the informal care relations. Certain cash benefits, especially the Dutch personal budget and the Italian and Austrian cash allowances, have resulted in an increase of the employment of unprofessional care workers, commonly hired on a private basis to work in people's homes. In all three countries, a large proportion of these unprofessional care workers are migrants. However, this ethnicisation of care work does not only happen in the undeclared economy, also service providers in the official economy recruit immigrants living in the country and attract people from abroad to work in the care sector, so the phenomenon of ethnicisation of care is also visible in countries with extensive formal care systems, such as Denmark, Norway and Sweden.

Parallel with formalisation and semi-formalisation of care, we see that in some countries the trend of informalisation is also detectable. This is more visible especially in some Nordic countries where the role of formal care from public services has for some time been an essential component of the elder care arrangements, but where these services have become more strictly targeted or even cut extensively. Informalisation can be understood as part of a larger development of privatisation of care where the responsibilities of organising, funding, and providing care are increasingly becoming private issues. This can result in 
not only the increasing importance of informal care, but also the recourse to grey market arrangements, volunteers and civil society at large.

Privatisation may also show itself in a form of marketisation, especially when referred to as privatisation of elder care in terms of funding. Marketisation of care happens when for-profit actors become more central in providing care services both sold in the market and as public services that are outsourced. The outsourcing of public services tends to be justified by the ideas of giving people more freedom to make choices regarding their care.

Choice has been a buzzword for many policy changes such as offering cash benefits, vouchers, tax rebates and a mix of service providers under the rubric of public care. The freedom to choose one's care is always exercised within limits as the alternatives are often few. Another way to call the ideology of choice is personalisation of care where users of services have a greater say in terms of design and delivery of services (Leadbeater 2004). The emphasis put on choice and personalisation has lead to a situation where older people and their relatives are increasingly acting as care managers: choosing, comparing, administering, and controlling various benefits, services and sources of care to ensure a continuous and encompassing care for the person in need. Choice-based and personalized care thus has the potential to lead to an individualisation of care where organising, providing and funding care is commonly an individual responsibility. This could be understood as a reverse process of politisation, the progressive withdrawal of public responsibility.

The receding public responsibility has its background in the monetisation of care where there is an increasing awareness of the economic costs of care. Care for older people is mainly seen as an expenditure that should be contained as it is a burden on the public funds. Still, monetisation does not manifest itself only at the government level. Instead it has been put into action at all levels of elder care. Regions and local governments that are responsible for implementing care policies apply principles of New Public Management and use private service providers that are found through tenders and bids as private providers are assumed to produce services more economically than public bodies. New tools such as care insurances are designed to collect contributions from the future beneficiaries, and for example in Finland and Sweden the user fees for public services have been increasing. Various cash benefits have intensified the presence of money in the sphere of informal care. Private consumption of services is boosted by tax rebates and vouchers that come with the possibility of topping up. Topping up means that if the voucher covers a certain amount of services produced by a market-based provider, then adding some own money one can get slightly more services.
This brief modern history of elder care policies and some practices serves as a background for the thematic section. The articles in this section address the policy changes and their consequences from the point of view of older people, care workers and informal carers by using different types of data and methods of analysis.

Tine Rostgaard and Marta Szebehely analyse the consequences of policy changes for the older people in Denmark and Sweden. Using comparable Level of Living survey data they show how Denmark has continued in the path of formalisation of elder care, whereas Sweden has diverged towards informalisation and marketisation of care.

Marketisation and monetisation of care are under scrutiny in the article written by Elin Kvist who evaluates the variety of policies encouraging people to directly purchase services to their homes in Austria, Belgium, Denmark, Finland, France, Germany and Sweden. She argues that care regimes are powerful trendsetters in envisaging the direction of these policies towards more or less formal employment of care workers.

Care workers are at the focus of the article by Gun-Britt Trydegård who evaluates the quality of care in relation to working conditions as reported in a survey by the care workers in Denmark, Finland, Norway and Sweden. Marketisation of care service provision seems to lead to an increasing standardization and regulation of care work with less room for good quality care. This is unfortunate as improvement of quality has been one of the main argument for the changes.

Good quality care is the target for older people in the article by Minna Zechner and Heli Valokivi where the negotiations on care in Finland and Italy are analysed using interviews with older people. The scattered, complicated and ever changing field of care has increasingly made older people as managers of their own care. This process of individualisation demands continuous negotiations which may be difficult to exercise exactly because of the need for care.

Care given by relatives is a complicated and multifaceted process as Blanche Le Bihan and Claude Martin point out in their article about employed carers in France, Italy, the Netherlands and Portugal. Using qualitative interview data, they make the semi-formalisation of care visible by pointing out how employed carers recourse to all possible sources of help when juggling work and care.

Professor Birgit Pfau-Effinger has kindly agreed to provide a discussion of the various articles in this thematic session. She places the articles into a wider comparative research context and stresses the consequences that changes in care policies have for elders in need of care, for care workers as well as for the quality of care. She also reminds us that care outcomes are not only direct outcomes of the 
care policies which are in place in a given national or local context, but are also an outcome of the broader framework of the complex and often contradictory cultural, institutional, social and economic context in the specific 'care arrangement' of the country.

As editors we warmly thank REASSESS for supporting the making of this thematic section. The received financial support allowed us to meet and discuss the progress of the articles. Also many thanks to our colleagues for contributing to the thematic session.

\section{References}

Geissler B, Pfau-Effinger B (2005) Change in European care arrangements. In: Pfau-Effinger B, Geissler B (eds) Care and social integration in European societies. Policy Press, Bristol, pp 3-19

Leadbeater C (2004) Personalisation through participation: a new script for public services. Demos, London 